\title{
Development of a Tool for Selection and Acquisition of Medical Devices based on the Analytic Hierarchy Process
}

\author{
V. Oliveira, J. Sobral, M. Margarida Ribeiro
}

\begin{abstract}
The existence of a tool to select and acquire Medical Devices is fundamental to manage the Life Cycle (LC) of Medical Devices (MD). The objective of this work is to create a structured, organized and optimized application to use on the selection and acquisition stage of a tender process, in order to help those responsible for the decision make. In addition it will turn the process exempt and transparent.

The methodology is based on a defined hierarchical multi criteria decision making approach, the Analytic Hierarchy Process (AHP) optimizing and validating all the requirements stated in a tender process and ensuring, free from human manipulation, that the best option will be chosen. The demonstrative study is applied to Computed Tomography (CT), with the aim of applying the methodology in the selection and acquisition of the best choice between four alternatives.

The developed tool includes some weights that are assigned to the established criteria and sub-criteria according to the present and future needs of each healthcare provider.

It has been proven that the price is not the only criteria, and perhaps not the most important. All technical and operational requirements as maintenance costs, availability, image quality, safety, and client satisfaction must also be included in the decision making process.
\end{abstract}

\section{INTRODUCTION}

According to the World Health Organization (WHO), in developed countries about half of medical equipment is not used correctly or optimally [1]. Despite health technology be a key element for health systems and for healthcare providers, it is often cited as one of the main factors leading to increased costs [1] [2] [3] [4]. Bearing all this in mind it is proposed the development of a systematic model of analysis with the objective of creating an optimized, structured and organized methodology to be used for the selection and acquisition of $\mathrm{MD}$, based on directives, national and international standards and using scientific models. It is proven that there is no inadequate technology, but simply most of the decision makers have difficulties in recognizing the needs and adapt them to their choices. This is an important topic for whom with responsibilities in this area or in the management of healthcare organizations.

V. Oliveira is with CHULS - Centro Hospitalar Universitário Lisboa Central, Lisboa, Portugal and with GLS - Grupo Lusíadas Saúde, Lisboa, Portugal (e-mail: vitanapn@gmail.com).

J. Sobral has a PhD in Mechanical Engineering and is with the Mechanical Engineering Department of Instituto Superior de Engenharia de Lisboa, Instituto Politécnico de Lisboa. Portugal and with CENTEC Centre for Marine Technology and Ocean Engineering, Lisboa, Portugal (email: jsobral@dem.isel.ipl.pt).

M. Margarida Ribeiro has a $\mathrm{PhD}$ in Life Sciences-Specility of Biotechnology and is with Scientific Área of Radiology of ESTeSL, Escola Superior de Tecnologia da Saúde de Lisboa, Instituto Politécnico de Lisboa. Portugal (e-mail: margarida.ribeiro@estesl.ipl.pt).
Healthcare providers are entities designed to assist people, prevent diseases, diagnose, treat, rehabilitate and conduct health research. Thus, they are considered to be complex organizations, both from the point of view of equipment engineering and installation, as well as in the technological and administration aspects.

The management of the LC of MD is a fundamental issue and can be defined as a process in which qualified professionals plan and manage the health technology. In the present work it was analyzed the point of view of a healthcare provider regarding the life cycle of MD including the following stages:

- Selection and Acquisition;

- Operation and Maintenance (O\&M);

- Deactivation (Dismantling or decommissioning).

Each one of these phases will correspond to a cost and the total of this cost over the life of the asset, gives the name of the Life Cycle Cost (LCC), or global cost [2] [5], which is used to select the solution with lower cost over of time [2]. In Figure 1, the different costs are shown schematically over time.

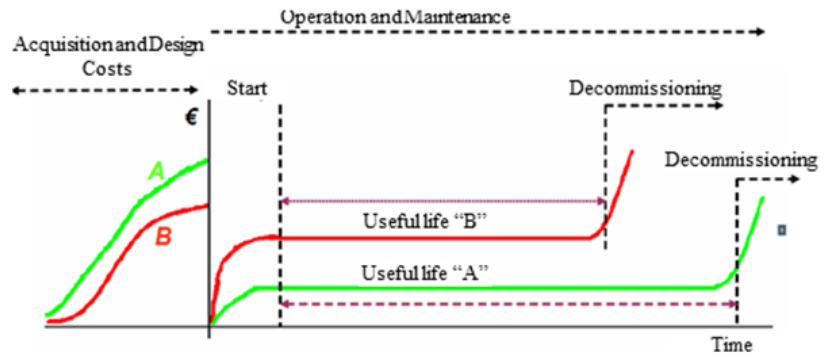

Figure 1. Asset life cycle, adapted from [6]

As it can be seen from Figure 1, asset " $A$ " has higher acquisition cost, but it will have reduced O\&M costs through its life cycle and with longer useful life. Table 2 presents different types of cost that will be considered in the present work and used on the demonstrative examples.

TABLE I. TYPE OF COSTS, BASED ON [7] [8]

\begin{tabular}{|l|l|}
\hline Type of Costs & Examples \\
\hline Acquisition Cost & Project, investment, tests \\
\hline Maintenance Cost & Maintenance Strategies \\
\hline Operating Cost & Human Resources, consumables \\
\hline Inactivity Cost & Maintenance, Breakdown Repair \\
\hline
\end{tabular}

In most cases radiological equipment, particularly $\mathrm{CT}$ Scans, as well as their characteristics should be chosen according to clinical criteria (pathology prevalent in the referenced population), demographic criteria (related to the population covered), economic criteria (cost-benefit) and operational criteria (durability, maintenance, among others 
mentioned throughout this study). It is verified, however, that these sometimes these are not the criteria taken into account in the selection and acquisition of MD.

This paper is structured into 5 sections. The first one gives a brief introduction to the theme and states the objective of the work developed. Section II describes the Analytic Hierarchy Process as the method used to select the best option between alternatives taking into account the established criteria. In section three there is a description of the proposed methodology. In section four there are some discussion about the results and in section five some conclusions and future works.

\section{ANALYTIC HIERARChy PROCESS}

The Analytic Hierarchy Process (AHP) is a widely used tool for decision making processes that involve alternatives and their numerical evaluation, being considered as a Multi Criteria Decision Making (MCDM). The methodology was firstly developed by Saaty (1980) corresponding to a simple way to analyze complex problems where subjective and objective factors are considered to make decisions.

The AHP process is used in complex decision problems and their evaluation is performed by weighting each attribute or alternative using a pair-wise comparison matrix [9].

The AHP can be applied to a huge variety of situations. Vaidya \& Kumar [10] developed a study showing an increasing number of papers dealing with AHP over time, most of them from USA (47\%) and Asia (33\%). It is also referred that AHP applications cover social, manufacturing, political, engineering and many others areas.

Triantaphyllou et al. [11] explained how Multi Criteria Decision Making methodologies are considered as critical decision tools for many scientific, financial, political and engineering challenges and used it to calculate the most important maintenance criteria among cost, capacity to repair, reliability and availability.

Hijes \& Cartagena [12] applied the methodology to classify equipment and support the decision for maintenance strategy. The authors started from the identification of critical equipment concluding with their quantification, called equipment criticality index, representing their criticality.

Bevilacqua \& Braglia [13] used the AHP process to select the maintenance strategy for an important Italian oil refinery involving five alternatives (preventive, predictive, conditionbased, corrective and opportunistic maintenance).

Other studies try to deal with uncertainty of the parameters or subjective judgements, using simulation approaches [14] or fuzzy logic [15] [16] [17].

AHP methodology starts with the definition of the decision criteria in the form of a hierarchy structured on different levels where the top level corresponds to the goal or overall objective. Next levels are related to criteria and subcriteria (if applicable) and the lowest level to the alternatives. Figure 2 shows the structure of AHP methodology for three defined criteria and five alternatives.

During the process, when comparing two criteria or alternatives there is a reciprocal relation that can be represented by a square matrix. After the judgement matrix has been developed, the eigenvector of the matrix is calculated in a way to weight the elements of the referred matrix.

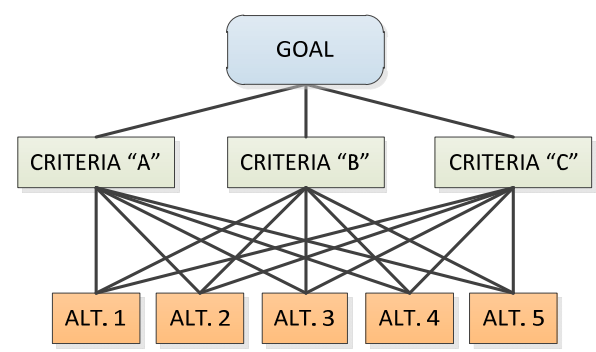

Figure 2. AHP structure

The judgement scores refer to Saaty scale using a discrete scale from 1 to 9 , as shown in Table II.

TABLE II. PAIRWISE COMPARISON SAATY'S SCALE

\begin{tabular}{|l|l|c|}
\hline Comparison & Explanation & Value \\
\hline Equally & $\begin{array}{l}\text { The two attributes contribute equally } \\
\text { to the upper-level criteria }\end{array}$ & 1 \\
\hline Moderately & $\begin{array}{l}\text { Experience and judgement slightly } \\
\text { favour one attribute over another }\end{array}$ & 3 \\
\hline Strongly & $\begin{array}{l}\text { Experience and judgement strongly } \\
\text { favour one attribute over another }\end{array}$ & 5 \\
\hline $\begin{array}{l}\text { Very } \\
\text { strongly }\end{array}$ & $\begin{array}{l}\text { One attribute is strongly favoured and } \\
\text { its dominance demonstrated in } \\
\text { practice }\end{array}$ & $\begin{array}{l}\text { The evidence favouring one attribute } \\
\text { over another is of highest possible } \\
\text { order of affirmation }\end{array}$ \\
\hline Extremely & \multicolumn{2}{|l}{} \\
\hline
\end{tabular}

The AHP methodology will be applied in Section III to weight criteria and sub-criteria and select the alternative that best fits on the selection and acquisition of a MD.

\section{Methodology Proposed}

Computed Tomography (CT) is used in the present study as an example because it is widely used in healthcare providers and because it represents a huge amount of money and a significant cost for this type of organizations. CT is considered as a Heavy Medical Device, with a useful life around 10 years [18]. The European Society of Radiology (ESR) recommends that each healthcare institution or authority should have a renewal plan for these equipment, meaning that [19]:

- Up to 5 years old - should not exceed $60 \%$ of the total;

- Age from 6 and 10 years old - should not exceed 30\%;

- Over 10 years old - should not exceed $10 \%$.

There must be a correct elaboration of tender documentation, in which the financial, legal (interests of the organizations, legal compliance, financial and technical guarantees never inferior to the LC of the MD and the respective sanctions in case of non-compliance are considered), technical and functional specifications (must be clear, not too tight, maintenance, safety and installation conditions, among others) demonstrates the minimum conditions of acceptability, as well as the elements that the customer needs and according to the nomenclatures, methods and evaluation units required. In order for the decision 
making process to be clear it is necessary that the tender documents include the criteria and sub-criteria (if exist), as well as their weights be defined taking into account to the present and future needs of the healthcare provider.

The methodology developed for the selection and acquisition process of a MD (in the present study, CT scan), relies on a hierarchical multi criteria decision approach and is based on the present and future needs of a healthcare provider. The tool was developed in the Microsoft Excel ${ }^{\mathrm{TM}}$ program, and the demonstrative example shows four "real" scenarios of $\mathrm{CT}$ acquisition proposals, through the definition and hierarchy of criteria and sub-criteria supported by the Analytic Hierarchy Process (AHP) briefly described in the previous section. The case studies performed were selected in a way to demonstrate that the selection of a MD can be different according to the requirements of each healthcare provider, even though using the same criteria and sub-criteria for all cases. Table III shows the criteria and sub-criteria used for the selection of a CT.

TABLE III. CRITERIA AND SUB-CRITERIA CONSIDERED

\begin{tabular}{|l|l|}
\hline \multicolumn{1}{|c|}{ Criteria } & \multicolumn{1}{c|}{ Sub-criteria } \\
\hline \multirow{4}{*}{ Total Life Cycle Cost } & Acquisition Costs \\
\cline { 2 - 2 } & Maintenance Costs \\
\cline { 2 - 2 } & Downtime Costs \\
\cline { 2 - 2 } $\begin{array}{l}\text { Global Operational } \\
\text { Assessment } \\
\text { (user's view) }\end{array}$ & Operational costs \\
\cline { 2 - 2 } & Image Quality \\
\cline { 2 - 2 } $\begin{array}{l}\text { Global Technical } \\
\text { Specifications } \\
\text { Assessment }\end{array}$ & CPU Operationality \\
\cline { 2 - 2 } & Graphic interface (user friendly) \\
\hline \multirow{2}{*}{$\begin{array}{l}\text { Mean Turn Around } \\
\text { Time }\end{array}$} & Radiation Dose \\
\cline { 2 - 2 } & Technical Characteristics \\
\cline { 2 - 2 } & Availab. of Specialized Tech. Resources \\
\cline { 2 - 2 } & Availab. of Stock of Wear Accessories \\
\hline
\end{tabular}

The structure of the referred criteria and sub-criteria methodology developed in the present work with the objective to select a MD is illustrated in Figure 3.

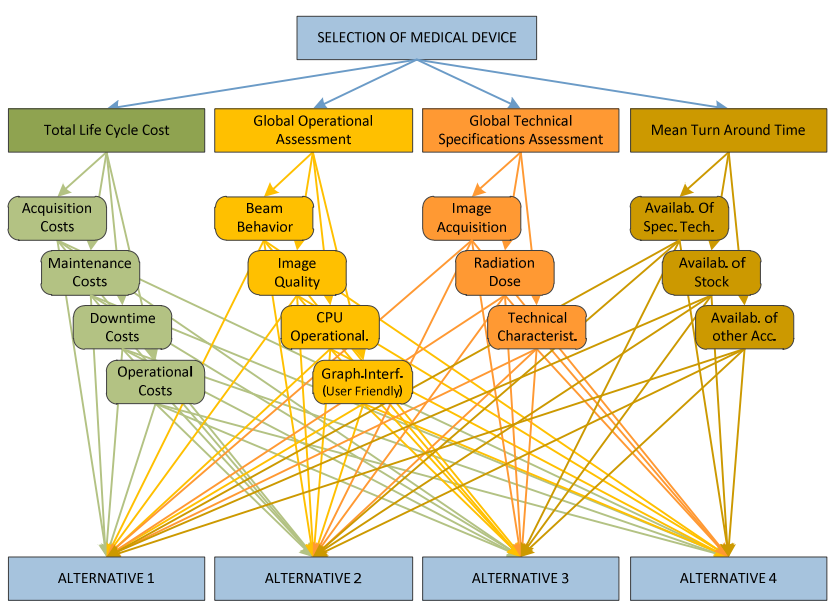

Figure 3. Structure for objective, criteria and sub-criteria

\section{RESUlTS AND DisCUSSION}

Using the tool developed it was analyzed all the costs and characteristics of each proposal and a quantification of them was achieved regarding all sub-criteria under consideration. Table IV shows the results achieved for the sub-criteria of criteria 1 , being possible to observe for each case study which alternative is the most appropriate.

TABLE IV. RESULTS FOR SUB-CRITERIA

\begin{tabular}{|c|c|c|c|c|c|}
\hline $\begin{array}{c}\text { Sub } \\
\text { Criteria }\end{array}$ & $\begin{array}{l}\text { Case } \\
\text { Study }\end{array}$ & $\begin{array}{c}\text { Altern. } \\
1\end{array}$ & $\begin{array}{c}\text { Altern. } \\
2\end{array}$ & $\begin{array}{c}\text { Altern. } \\
3\end{array}$ & $\begin{array}{c}\text { Altern. } \\
4\end{array}$ \\
\hline \multirow{4}{*}{$\begin{array}{c}\text { SC1.1 } \\
\text { Acquisit. } \\
\text { Costs }\end{array}$} & I & $3,75 \%$ & $3,57 \%$ & $2,96 \%$ & $2,68 \%$ \\
\hline & II & $16,91 \%$ & $16,49 \%$ & $13,84 \%$ & $12,76 \%$ \\
\hline & III & $7,62 \%$ & $7,33 \%$ & $5,98 \%$ & $5,47 \%$ \\
\hline & IV & $12,76 \%$ & $11,93 \%$ & $9,92 \%$ & $9,02 \%$ \\
\hline \multicolumn{2}{|c|}{ Average } & $10,26 \%$ & $9,83 \%$ & $8.18 \%$ & $7.48 \%$ \\
\hline \multirow{4}{*}{$\begin{array}{c}\text { SC1.2 } \\
\text { Maint. } \\
\text { Costs }\end{array}$} & I & $3,88 \%$ & $4,86 \%$ & $6,55 \%$ & $6,81 \%$ \\
\hline & II & $4,90 \%$ & $4,22 \%$ & $6,92 \%$ & $6,55 \%$ \\
\hline & III & $7,78 \%$ & $7,95 \%$ & $11,73 \%$ & $11,38 \%$ \\
\hline & IV & $6,22 \%$ & $9,27 \%$ & $12,10 \%$ & $12,62 \%$ \\
\hline \multicolumn{2}{|c|}{ Average } & $5,70 \%$ & $6,58 \%$ & $9,33 \%$ & $9,34 \%$ \\
\hline \multirow{4}{*}{$\begin{array}{c}\text { SC1.3 } \\
\text { Downt. } \\
\text { Costs }\end{array}$} & I & $5,53 \%$ & $5,49 \%$ & $5,42 \%$ & $5,42 \%$ \\
\hline & II & $4,68 \%$ & $4,75 \%$ & $4,75 \%$ & $4,83 \%$ \\
\hline & III & $7,38 \%$ & $7,39 \%$ & $7,18 \%$ & $7,25 \%$ \\
\hline & IV & $7,07 \%$ & $6,87 \%$ & $6,80 \%$ & $6,84 \%$ \\
\hline \multicolumn{2}{|c|}{ Average } & $6,17 \%$ & $6,13 \%$ & $6,04 \%$ & $6,09 \%$ \\
\hline \multirow{4}{*}{$\begin{array}{c}\text { SC1.4 } \\
\text { Operat. } \\
\text { Costs }\end{array}$} & $\mathrm{I}$ & $86,88 \%$ & $86,08 \%$ & $85,07 \%$ & $85,09 \%$ \\
\hline & II & $73,51 \%$ & $74,54 \%$ & $74,49 \%$ & $75,86 \%$ \\
\hline & III & $77,23 \%$ & $77,33 \%$ & $75,11 \%$ & $75,90 \%$ \\
\hline & IV & $73,95 \%$ & $71,92 \%$ & $71,17 \%$ & $71,53 \%$ \\
\hline \multicolumn{2}{|c|}{ Average } & $77,89 \%$ & $77,47 \%$ & $76,46 \%$ & $77,10 \%$ \\
\hline
\end{tabular}

Based on the present study it can be seen that the acquisition cost only represents an average of about $8.94 \%$ of total life cycle cost, thus it cannot be the only or main decision factor. Table $\mathrm{V}$ refers to the maintenance costs and all-inclusive maintenance costs, excluding $\mathrm{X}$-ray source.

TABLE V. MAINTENANCE COSTS

\begin{tabular}{|c|c|c|c|c|c|c|c|c|}
\hline \multirow{2}{*}{$\begin{array}{c}\text { ALTER } \\
\text { N. }\end{array}$} & \multicolumn{2}{|c|}{$\boldsymbol{I}$} & \multicolumn{2}{|c|}{$\boldsymbol{I}$} & \multicolumn{2}{|c|}{$\boldsymbol{I I I}$} & \multicolumn{2}{|c|}{$\boldsymbol{I V}$} \\
\cline { 2 - 9 } & $\mathrm{k} €$ & $\%$ & $\mathrm{k} €$ & $\%$ & $\mathrm{k} €$ & $\%$ & $\mathrm{k} €$ & $\%$ \\
\hline A1 & 269 & 12,3 & 75 & 43,9 & 265 & 12,4 & 127 & 26,1 \\
\hline A2 & 340 & 18,8 & 64 & 100,0 & & 23,6 & 194 & 32,9 \\
\hline A3 & 464 & 11,8 & 55 & 52,1 & 412 & 13,3 & 256 & 21,4 \\
\hline A4 & 482 & 11,3 & 54 & 55,8 & 395 & 13,8 & 266 & 20,5 \\
\hline AV. & & 13,6 & & 62,9 & & 15,8 & & 25.2 \\
\hline
\end{tabular}

Regarding at the previous table it can be seen that the value of the X-ray sources (not shown) represents, on average, more than $70 \%$ of maintenance costs.

Taking into account the needs presented at each one of the situations (case studies), and after performing the proposed methodology, the results show that for Case Study 1 was chosen Alternative 2, with a preference of $51.94 \%$, for Case Study 2 was chosen Alternative 4, with a preference of $40.52 \%$, for Case Study 3 was chosen Alternative 1, with a 
preference of $38.81 \%$ and for Case Study 4 the chosen one was Alternative 3, with a preference of $35.38 \%$. These results are detailed in Table VI and graphically represented in Figure 4, showing the best alternative for each case study.

TABLE VI. RESULTS OF DEMONSTRATIVE EXAMPLE

\begin{tabular}{|l|c|c|c|c|c|c|c|c|}
\hline \multirow{2}{*}{ Altern. } & \multicolumn{2}{|c|}{$\begin{array}{c}\text { Case Study } \\
\text { I }\end{array}$} & \multicolumn{2}{c|}{$\begin{array}{c}\text { Case Study } \\
\text { II }\end{array}$} & $\begin{array}{c}\text { Case Study } \\
\text { III }\end{array}$ & \multicolumn{2}{c|}{$\begin{array}{c}\text { Case Study } \\
\text { IV }\end{array}$} \\
\cline { 2 - 10 } & Result & Rank & Result & Rank & Result & Rank & Result & Rank \\
\hline A1 & 0,2415 & 2 & 0,1498 & 3 & $\mathbf{0 , 3 8 8 1}$ & 1 & 0,1720 & 4 \\
\hline A2 & $\mathbf{0 , 5 1 9 4}$ & 1 & 0,1359 & 4 & 0,2384 & 2 & 0,2109 & 3 \\
\hline A3 & 0,1202 & 3 & 0,3091 & 2 & 0,2266 & 3 & $\mathbf{0 , 3 5 3 8}$ & 1 \\
\hline A4 & 0,1189 & 4 & $\mathbf{0 , 4 0 5 2}$ & 1 & 0,1469 & 4 & 0,2633 & 2 \\
\hline Select & \multicolumn{2}{|c|}{ A2 } & \multicolumn{2}{|c|}{ A4 } & \multicolumn{2}{c|}{ A1 } & \multicolumn{2}{|c|}{ A3 } \\
\hline
\end{tabular}

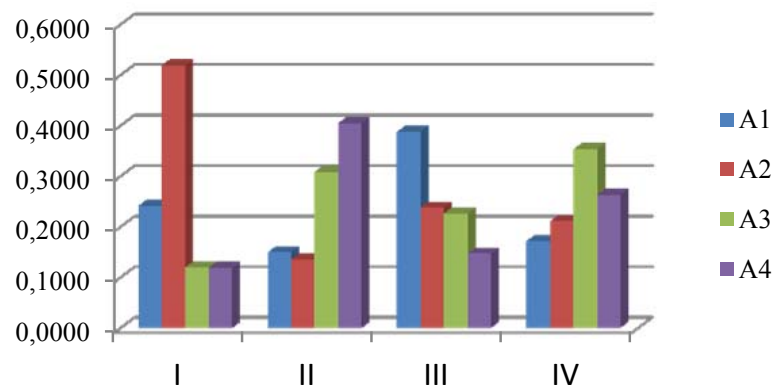

Figure 4. Selection of best Alternative

The results demonstrate that the chosen alternative for MD depends on multiple factors, on the operational and maintenance requirements and on the objectives of each healthcare provider. Thus, it is important to establish the criteria and sub-criteria for each case and compare all the alternatives placed on the table in a way to select the one that best fits those objectives. The proposed methodology allows doing that in a clear process.

\section{CONCLUSIONS}

The selection and acquisition should be performed by a multidisciplinary team, consisting of healthcare professional (operational and clinical approach), hospital administrators (strategic and economic perspective) and engineers (technical vision and leadership). This selection must be based on defined criteria that should be established in accordance to the operational and strategic objectives of each healthcare provider. The definition and weighting of criteria and sub-criteria must be done considering the value of the MD in function of the present and future needs of the healthcare provider. The proposed methodology may be an useful tool to assist in definition of the structure of a tender process and on the organization for the selection of the best alternative among all, and in a quantified way.

It helps to analyze and prioritize criteria and sub-criteria, evaluate the total cost of life cycle and effectiveness of each proposal, analyzing costs, quality, satisfaction and risk, among others. It must also be referred that with the application of the proposed methodology tender processes become clear and exempt. The methodology can be adjusted, for example, according the changes of disease patterns, population density, and demographic areas of the reference, geographic or health care policies. As future works it can be said that this tool can be integrated in an asset management philosophy, developing an incorporated module regarding the selection and acquisition processes, with a user friendly interface. The proposed methodology can be applied to other medical devices than CT Scans, being a useful tool for any healthcare provider or other type of institution where assets play an important role.

\section{REFERENCES}

[1] Santos, C.S.M. (2012). Assessment of Medical Devices. The application of HTA Core Model of EUnetHTA (in portuguese). MSc Thesis - Universidade de Coimbra. Coimbra, Portugal

[2] Heleno, B.C. (2014). Application of Reliability Centred Maintenance to Medical Devices (in portuguese). MSc Thesis - Universidade Católica Portuguesa. Lisboa, Portugal

[3] Manso, J.M.D. (2012). Medical Equipment Management Practices at Hospital da Luz (in portuguese). MSc Thesis - Universidade de Lisboa. Lisboa, Portugal

[4] Nascimento, L.N. (2008). A Method for Evaluating Costs of Hospital Medical Equipment in Health Care Procedures (in portuguese). MSc Thesis - Universidade Estadual de Campinas. Campinas, Brazil

[5] Assis, R. (2014). Support to the Maintenance Decision in the Management of Physical Assets (in portuguese). 2nd Edition. Ed. LIDEL. Lisboa, Portugal

[6] GIAGI (2007). Equipment Maintenance and Availability Management (in portuguese). $1^{\text {a }}$ Edição. GIAGI - Consultores em Gestão Industrial. Aveiro, Portugal

[7] Assis, R. and Julião, J. (2009). Maintenance Management or Asset Management (in portuguese). Available online at: https://www.researchgate.net/publication/266522175

[8] Ahang, G. and Wang, W. (2012). The Research of Comprehensive Evaluation Model for Thermal Power Equipment Based on Life Cycle Cost. Systems Engineering Procedia, vol. 4, pp. 68-78

[9] Zhong, L. and Youchao, S. (2007). Research on Maintainability Evaluation Model Based on Fuzzy Theory. Chinese Journal of Aeronautics 20, pp. 402-407

[10] Vaidya, O.S. and Kumar, S. (2006). Analytic hierarchy process: An overview of applications. European Journal of Operational Research 169 , pp. 1-29

[11] Triantaphyllou, E., Kovalerchuk, B., Mann, L. and Knapp, G.M. (1997). Determining the most important criteria in maintenance decision making. Journal of Quality in Maintenance Engineering 3(1), pp. $16-28$

[12] Hijes, F. and Cartagena, J. (2006). Maintenance strategy based on a multicriterion classification of equipments. Reliability Engineering \& System Safety 91, pp. 444-451

[13] Bevilacqua, M. and Braglia, M. (2000). The analytic hierarchy process applied to maintenance strategy selection. Reliability Engineering \& System Safety 70, pp. 71-83

[14] Levary, R. and Wan, K. (1998). A simulation approach for handling uncertainty in the analytic hierarchy process. European Journal of Operational Research 106, pp. 116-122

[15] Braglia, M. and Bevilacqua, M. (2000). Fuzzy modelling and analytical hierarchy processing as a means of quantifying risk levels associated with failure modes in production systems. Technology, Law and Insurance 5, pp. 125-134

[16] Al-Najjar, B. and Alsyouf, I. (2003). Selecting the most efficient maintenance approach using fuzzy multiple criteria decision making. International Journal of Production Economics 84, pp. 85-100

[17] Dagdeviren, M. and Yuksel, I. (2008). Developing a fuzzy analytic hierarchy process (AHP) model for behavior-based safety management. Information Sciences 178, pp. 1717-1733

[18] Penedo, J., Madahil, A., Ferreira, A., Nunes, A., Pereira, J., Venâncio, J., Maia, M. and Alves, P. (2013). Document of Heavy Medical Equipment (in portuguese). Ministério da Saúde, Lisboa, Portugal

[19] ESR (2014). Renewal of Radiological Equipment. Insights Imaging, vol. 5 , pp. 543-546 